\title{
Efektivitas E-modul Getaran Dalam Kehidupan Sehari- Hari Pada Pembelajaran Daring Untuk Meningkatkan Keterampilan Proses Sains Siswa
}

\author{
Aditya Fahlevi \& Asrizal* \\ Pendidikan Fisika, Universitas Negeri Padang \\ *Email: asrizal@fmipa.unp.ac.id
}

Received: 2 Oktober 2021; $\quad$ Accepted: 23 Oktober 2021; $\quad$ Published: 26 November 2021 DOI: http://dx.doi.org/10.29303/jpft.v7i2.2997

\begin{abstract}
Physics learning has a central role in developing the $21^{\text {st }}$ century skills that learners must achieve. Physics aksis one of science learning can cultivate and develop $21^{\text {st }}$ century skills through science literacy and science process skills. Science process skills can be trained in the learning of physics through processes in conducting scientific activities and scientific attitudes. But from the initial studies conducted, it was found that the ability of the student's science process in online learning has artistic variety of problems. One alternative to problem solving is to use electronic modules (e-modules) designed to improve students' science process skills in online learning. The methodology used in this study was a quasi-experiment with the design of the posttest only control research design group. The aim of the study was to determine the effectiveness of the use of e-modules of vibration in everyday life on online learning to improve the science process skills of grade $X$ high school students. The effectiveness of e-module use is determined by analyzing the science process skills of experimental classroom and control classes. The significance of the effectiveness of the use of e-modules on aspects of knowledge and skills of the science process is analyzed by tests of normality, homogeneity and $t$ tests. From the analysis of data obtained by the results of the study, the use of vibrational emodules in everyday life in online learning is effective to improve students' knowledge and skills of the science process.
\end{abstract}

Keywords: E-Module of Vibration; Online Learning; Science Prosess Skill

\section{PENDAHULUAN}

Keterampilan abad 21 perlu dibekalkan kepada peserta didik untuk menghadapi tantangan di bidang IPTEK. Hal ini bertujuan agar siswa mampu bersaing dengan baik di era globalisasi. Melalui pembelajaran di era digital diharapkan dapat membentuk suatu mindset manusia abad 21. Pelaksanaan pembelajaran oleh satuan pendidikan harus mampu meningkatkan dan mengembangkan kompetensi abad ke-21 yang harus dicapai oleh siswa (Asrizal et al., 2018). Pelaksanaan pembelajaran pada abad 21 menuntut siswa untuk terampil, memiliki pengetahuan yang luas, pengetahuan dan keterampilan di bidang teknologi informasi (Wijaya, et al. 2016). Sejalan dengan hal itu, Turiman et al (2011) menyebutkan bahwa keterampilan abad 21 terdiri dari empat domain utama yaitu literasi era digital, berpikir inventif, komunikasi efektif dan produktivitas tinggi.

Pengembangan keterampilan abad 21 dapat dilakukan melalui disiplin ilmu fisika. Pengajaran fisika pada satuan pendidikan memiliki kedudukan yang sentral untuk mengembangkan keterampilan abad 21 peserta didik (Desy, et al., 2017). Pembelajaran fisika sebagai salah satu pembelajaran sains dapat menggabungkan berbagai aspek keterampilan dan memiliki potensi untuk melatih keterampilan abad 21 yang harus dicapai siswa. Sejalan dengan pendapat Turiman et al, (2011) yang menyebutkan bahwa keterampilan abad 21 yang harus dicapai dapat dilakukan melalui pembelajaran yang melatih literasi sains dan keterampilan proses sains, terutama bagi siswa yang mengikuti pembelajaran sains. 
Penguasaan konsep dan pencapaian kompetensi lulusan dalam pembelajaran fisika dapat diperoleh melalui pembelajaran yang melibatkan siswa secara langsung. Hal ini akan memicu siswa berperan lebih aktif dan kreatif untuk memperoleh pengalamanpengalaman ilmiah sehingga pembelajaran menjadi lebih bermakna. Pembelajaran bermakna dapat dijelaskan sebagai suatu proses pembelajaran dimana siswa secara langsung mengalami suatu peristiwa selama pembelajaran tersebut sehingga mereka dapat menyimpan informasi yang diterimanya dalam kurun waktu yang lama (Asrizal et al. 2018). Untuk mencapai hal tersebut, pembelajaran fisika dapat dilaksanakan melalui proses melakukan kegiatan ilmiah yang dikenal dengan keterampilan proses sains (Tawil \& Liliasari, 2014). Oleh karena itu, penting bagi siswa untuk memperoleh keterampilan proses sains agar menjadi siswa yang aktif.

Namun terdapat indikasi kesenjangan antara kondisi nyata dengan yang diharapkan di salah satu sekolah di Kabupaten Kerinci. Kondisi nyata yang pertama berhubungan dengan kegiatan eksperimen. Berdasarkan data hasil wawancara, diketahui bahwa kegiatan eksperimen dalam proses pembelajaran di sekolah tersebut tidak terlaksana. Hal ini mengakibatkan banyaknya kemampuan proses yang tidak didapatkan oleh siswa Kondisi nyata kedua berhubungan dengan pelaksanaan pembelajaran daring. Berdasarkan observasi diperoleh hasil bahwa keterlaksanaan kegiatan pendahuluan yaitu $75 \%$, kegiatan inti 50\%, dan kegiatan penutup 79\%. Dari data tersebut dan berdasarkan analisis terhadap indikatorindikator yang diukur dapat dinyatakan bahwa pelaksanaan pembelajaran daring di sekolah tersebut tidak mendukung terlaksananya kegiatan belajar yang melatih keterampilan proses sains. Kondisi nyata ketiga berhubungan dengan hasil belajar fisika siswa. Data hasil belajar fisika siswa merupakan data sekunder yang diperoleh dari hasil Penilaian Tengah Semester (PTS) pada semester ganjil tahun 2020. Data yang diperoleh menunjukkan bahwa hasil belajar fisika siswa kelas X MIPA masih berada dalam kategori rendah

Penelitian tentang pengaruh modul baik cetak maupun elektronik terhadap kemampuan keterampilan proses sains sudah dilakukan oleh beberapa peneliti sebelumnya. Mayanty, et al. (2018) menyatakan bahwa modul digital dapat merangsang siswa untuk belajar secara mandiri dan memiliki kriteria sangat baik dan layak digunakan sebagai bahan ajar untuk melatih keterampilan proses sains. Penelitian kedua oleh Ardiva \& Andini (2019) yang memperoleh kesimpulan bahwa e-modul fisika efiktif untuk meningkatkan keterampilan proses sains dengan kategori "sedang".

Penelitian yang telah dilakukan tersebut memiliki kesamaan yang mendukung dan memiliki perbedaan dengan penelitian yang dilakukan oleh peneliti. Perbedaan pertama e-modul yang digunakan berupa e-modul dalam bentuk aplikasi berbasis android yang dikembangkan menggunakan MIT App Inventor. Kedua, materi pembelajaran dalam e-modul yaitu materi tentang getaran harmonis sederhana. Ketiga, penelitian efektivitas e-modul dilakukan pada pembelajaran daring.

Modul adalah suatu bentuk bahan ajar yang disusun secara sistematis. Modul sebagai bahan didaktis merupakan komponen pembelajaran yang memegang peranan penting dalam pencapaian kompetensi pembelajaran. (Asrizal et al. 2014). Bahan ajar disusun untuk memudahkan guru sebagai pengajar dalam menyampaikan materi pembelajaran serta 
pesan pembelajaran kepada peserta didik, sehingga pembelajaran dengan bahan ajar dapat merangsang pikiran peserta didik, serta minat atau motivasinya untuk belajar (Serevina et al, 2018). Salah satu fungsi modul yaitu sebagai alat belajar mandiri sehingga siswa dapat belajar dengan menyesuaikan kecepatannya sendiri. (Sutrisno, 2008). E-modul sebagai suatu bahan ajar, menuntuk siswa untuk belajar secara mandiri dalam menumukan suatu konsep (Enrica \& Hardeli, 2019: 813). Dengan E-modul, proses pembelajaran dirancang baik audiovisual maupun interaktif, sehingga aplikasinya mudah dipahami dan dapat digunakan sebagai media pembelajaran yang baik. (Sugianto et al, 2013).

Pembelajaran menggunakan e-modul dapat dilakukan pada pembelajaran daring. Pembelajaran daring adalah pembelajaran yang berlangsung melalui jaringan web (Bilfaqih, \& Nur, 2015). Pembelajaran daring berlangsung di dalam jaringan dimana pengajar dan yang diajar tidak bertatap muka secara langsung (Pohan, 2020). Pembelajaran daring juga dapat diartikan sebagai pembelajaran melalui pemanfaatan teknologi multimedia, kelas virtual, CD-ROM, video streaming, pesan suara, email dan panggilan konferensi, teks animasi online, dan video streaming online. (Kuntarto, 2017).

Bertitik tolak pada latar belakang masalah yang telah diuraikan, maka penelitian tentang pengaruh penggunaan emodul perlu dilakukan. Hal ini berlandaskan bahwa untuk mendapatkan e-modul sebagai bahan pembelajaran yang baik, perlu dilakukan analisis terhadap kualitas e-modul yang dikembangkan (Febrilia., Ratnawulan., \& Usmeldi, 2019). Tujuan dari penelitian ini yaitu untuk menentukan pengaruh penggunaan e-modul getaran dalam kehidupan sehari-hari pada pembelajaran daring terhadap keterampilan proses sains siswa kelas X SMA.

\section{METODE PENELITIAN}

Penelitian ini menggunakan metode Eksperimen Semu (Quasi Eksperimental). Desain penelitian ini memiliki kelompok kontrol, tetapi tidak dapat sepenuhnya berfungsi untuk mengontrol variabel eksternal yang mempengaruhi pelaksanaan eksperimen. Desain eksperimen ini menggunakan PosttestOnly Control Design. Ada dua kelompok dalam desain ini, yang masing-masing dipilih secara acak (R). Kedua kelompok diajar menggunakan Google Classroom dengan kelompok pertama diberi perlakuan (X) yaitu penggunaan e-modul getaran dalam kehidupan sehari-hari pada pembelajaran daring dan kelompok yang lain tidak. Desain penelitian ini dapat digambarkan sebagai berikut.

\begin{tabular}{|lll|}
\hline$R$ & $X$ & $O 1$ \\
$R$ & & $O 2$ \\
\hline
\end{tabular}

Gambar 1. Desain Penelitian Posttest-Only Control Grup Desain

Kelompok perlakuan ditetapkan sebagai kelompok eksperimen dan kelompok yang tidak diberi perlakuan sebagai kelompok kontrol. Pengaruh perlakuan (treatment) adalah $(\mathrm{O} 1: \mathrm{O} 2)$ yaitu hasil belajar siswa pada aspek pengetahuan dan aspek keterampilan proses sains. Untuk menguji signifikansi efektivitas penggunaan e-modul digunakan uji perbandingan dua cara, yaitu uji-t.

Populasi dalam penelitian ini adalah seluruh siswa kelas X MIPA yang berjumlah 78 orang. Populasi terdiri dari 4 kelas yang diajar oleh guru yang sama. Sampel dalam penelitian ini adalah Kelas X MIPA 2 dan X MIPA 4. Prosedur yang digunakan dalam 
pengambilan sampel acak ini adalah prosedur undian.

Tahapan analisis data yaitu: 1) uji normalitas menggunakan uji Liliefors pada taraf nyata $\alpha=0,05$. Adapun kriteria normalitas yaitu jika Lo $\leq$ Lt. 2) Uji homogenitas dengan menggunakan uji $\mathrm{F}$. Adapaun kriteria varians homogen apabila nilai $F_{h} \leq F_{t}$. 3) Uji Perbandingan dua ratarata dengan menggunakan uji-t independen t-test dua pihak.

\section{HASIL DAN PEMBAHASAN}

Efektivitas penggunaan e-modul getaran dalam kehidupan sehari-hari pada pembelajaran daring didapatkan setelah dilakukan eksperimen semu. pengaruh penggunaan e-modul dalam pembelajaran dilihat dari perbandingan hasil belajar aspek pengetahuan dan aspek keterampilan proses sains siswa kelas eksperimen dengan kelas kontrol. Nilai pengetahuan siswa diperoleh melalui soal tes berbentuk pilihan ganda sementara nilai keterampilan proses sains siswa diperoleh melalui observasi dengan menggunakan lembar kinerja. Tes penilaian pengetahuan dilakukan pada pertemuan terakhir melalui googleform sementara kemampuan keterampilan proses sains siswa diukur dengan menggunakan lembar kinerja pada saat proses pembelajaran berlangsung serta laporan kegiatan observasi dan laporan eksperimen siswa.

\section{Hasil}

a. Efektivitas Penggunaan E-modul Terhadap Aspek Pengetahuan

Hasil belajar siswa pada aspek pengetahuan diukur dengan menggunakan instrumen berupa tes setelah penggunaan emodul getaran dalam kehidupan sehari-hari pada pembelajaran daring. Tujuan dilakukan tes pada aspek pengetahuan yaitu untuk menilai sejauh mana pengaruh e-modul untuk meningkatkan pemahaman konsep siswa terhadap materi pembelajaran. Hasil analisis data aspek pengetahuan dapat dilihat pada Tabel 1.

Tabel 1. Hasil Analisis Data Aspek Pengetahuan

\begin{tabular}{clcc}
\hline No & Statistik & Eksperimen & Kontrol \\
\hline 1 & Rata-rata & 76 & 68 \\
2 & Standar & 14,97 & 16,54 \\
& Deviasi & & \\
3 & Uji & Normal & Normal \\
& normalitas & & \\
4 & Uji & \multicolumn{2}{c}{ Homogen } \\
& homogenitas & \multicolumn{2}{c}{2,12} \\
5 & Uji t' & \multicolumn{2}{c}{} \\
\hline
\end{tabular}

Berdasarkan data yang ditampilkan dalam Tabel 1 dapat dijelaskan bahwa terdapat perbedaan nilai rata-rata aspek pengetahuan kelas eksperimen dengan kelas kontrol. Nilai rata-rata kelas eksperimen lebih tinggi dari nilai rata-rata kelas kontrol. Hal ini menunjukkan bahwa terdapat pengaruh dari perlakuan yang diberikan pada kelas sampel. Data dari kedua kelas ini tergolong normal dan homogen. Signifikansi efektivitas penggunaan e-modul terhadap hasil belajar siswa pada aspek pengetahuan dilakukan dengan uji perbandingan dua ratarata menggunakan uji t. Harga th yang didapatkan dari analisis statistik dengan uji t-test independent yaitu sebesar 2,12. Sementara harga tt dengan $\mathrm{dk}=35+35-2$ $=68$ adalah sebesar 1,99 pada taraf nyata $\alpha$ $=0,05$. Dari data tersebut diketahui bahwa harga th lebih besar daripada tt (thitung > ttabel), hal ini menunjukkan bahwa terdapat perbedaan yang signifikan antara pengetahuan siswa kelas eksperimen dengan kelas kontrol. Dengan demikian, dapat disimpulkan bahwa penggunaan e-modul getaran dalam kehidupan sehari-hari pada pembelajaran daring memiliki pengaruh yang signifikan terhadap pengetahuan siswa
b. Efektivitas Penggunaan E-modul Terhadap Aspek Keterampilan Proses Sains 
Pengaruh penggunaan e-modul dalam pembelajaran juga dilihat dari perbandingan hasil belajar aspek keterampilan proses sains siswa kelas eksperimen dengan kelas kontrol. Keterampilan proses sains siswa diukur selama tiga kali pertemuan. Keterampilan proses sains yang dinilai pada pembelajaran terdiri dari enam komponen. Komponenkomponen tersebut yaitu: 1) observasi (OB), 2) perumusan hipotesis $(\mathrm{PH}), 3$ ) interpretasi data (ID), 4) pengajuan pertanyaan (PP), 5) eksperimen (EK), 6) komunikasi (KM). Hasil plot data dari komponen keterampilan proses sains dapat dilihat pada Gambar 2.

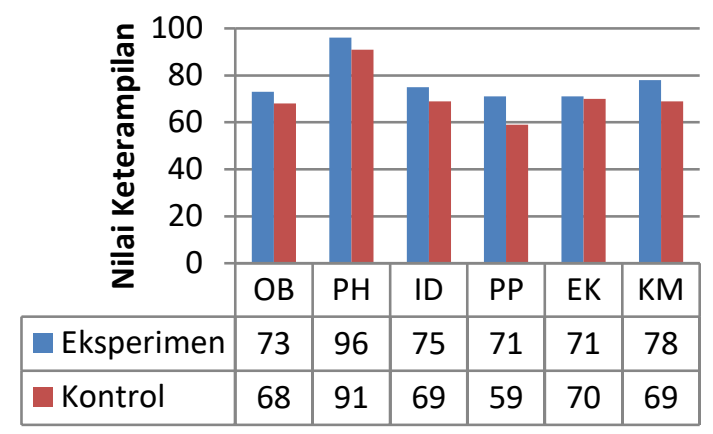

Gambar 2. Nilai keterampilan siswa perkomponen

Berdasarkan analisis data pada Gambar 2 dapat dideskripsikan nilai keterampilan siswa per-komponen untuk kedua kelas sampel. Nilai rata-rata perkomponen yang ditampilkan menunjukkan perbedaan nilai keterampilan antara kelas eksperimen dengan kelas kontrol. Analisis data perbedaan nilai rata-rata kelas eksperimen dengan kelas kontrol juga dapat ditampilkan dalam bentuk tabel. Pada tabel disajikan lebih rinci parameter statistik yang digunakan untuk menentukan pengaruh penggunaan e-modul. Hasil analisis statistik data aspek keterampilan dapat dilihat pada Tabel 2.
Tabel 2. Hasil Analisis Data Aspek Keterampilan Proses Sains

\begin{tabular}{clcc}
\hline No & Statistik & Eksperimen & Kontrol \\
\hline 1 & Rata-rata & 77 & 71 \\
2 & Standar & 7,35 & 6,10 \\
& Deviasi & & \\
3 & Uji & Normal & Normal \\
& normalitas & & \\
4 & Uji & \multicolumn{2}{c}{ Homogen } \\
& homogenitas & \multicolumn{2}{c}{3,074} \\
5 & Uji t' & \multicolumn{2}{c}{} \\
\hline
\end{tabular}

Berdasarkan Tabel 2 dapat dijelaskan bahwa keterampilan proses sains antara kedua kelas sampel memiliki perbedaan nilai rata-rata. Nilai rata-rata kelas eksperimen lebih tinggi dari nilai rata-rata kelas kontrol. Hal ini menunjukkan bahwa terdapat pengaruh dari perlakuan yang diberikan pada kelas sampel.

Untuk menguji signifikansi pengaruh atau efektivitas penggunaan e-modul getaran dalam kehidupan sehari-hari pada pembelajaran daring untuk meningkatkan keterampilan proses sains siswa maka perlu dilakukan uji perbandingan dua rata-rata menggunakan uji t. Hasil uji t menunjukkan Harga th yang didapatkan dari analisis statistik yaitu sebesar 3,704. Sementara harga tt dengan $\mathrm{dk}=35+35-2=68$ adalah sebesar 1,99 pada taraf nyata $\alpha=0,05$. Dari data tersebut diketahui bahwa harga th lebih besar daripada $t$ t (thitung > tabel), hal ini menunjukkan bahwa terdapat perbedaan yang signifikan antara keterampilan proses sains siswa kelas eksperimen dengan kelas kontrol.

\section{Pembahasan}

Penggunaan e-modul getaran dalam kehidupan sehari-hari pada pembelajaran daring, adalah efektif untuk meningkatkan pengetahuan dan keterampilan proses sains siswa. Hal ini dianalisis dari adanya perbedaan antara rata-rata nilai pengetahuan dan keterampilan proses sains kedua 
kelompok sampel. Adanya perbedaan ini disebabkan oleh penggunaan e-modul yang telah dirancang agar tercapai suatu tujuan yaitu kegiatan belajar yang efektif dan memiliki pengaruh terhadap peningkatan pengetahuan dan keterampilan proses sains siswa. E-modul yang terintegrasi dengan sistem android memiliki dampak yang positif terhadap performa belajar peserta didik (Tazkiyah et al. 2020). Penggunaan modul elektronik juga dapat membantu dalam melatih sifat kemandirian peserta didik dalam menemukan konsep-konsep dalam suatu pembelajaran (Mayanti, 2018).

E-modul getaran dalam kehidupan sehari-hari pada pembelajaran daring memiliki pengaruh yang positif terhadap aspek pengetahuan karena e-modul ini dapat digunakan sesuai kebutuhan peserta didik. E-modul sebagai materi didaktik dianggap memadai dengan memperhatikan perbedaan tingkat dan kecepatan belajar siswa (Prastowo, 2015). Dengan adanya e-modul, siswa dapat dengan mudah untuk mengulangi pembelajaran kembali. E-modul yang digunakan juga bersifat interaktif dan mengintegrasikan komponen audio visual seperti video pembelajaran yang dekat dengan kehidupan nyata sehingga menjadikan e-modul sebagai alternatif bahan pembelajaran yang baik. Modul elektronik dapat secara efektif menyampaikan pesan pembelajaran dari guru kepada siswa. Hal ini didasarkan pada e-modul yang merupakan bagian dari elearning, dimana penggunaan elearning dalam pembelajaran membuat proses pembelajaran dapat dilakukan secara terus menerus (Darmaji et al. 2019). Pembelajaran fisika dengan e-modul yang terintegrasi dengan kegiatan eksperimen virtual terbukti mampu meningkatkan hasil belajar siswa (Muthmainnah et al. 2017).

E-modul getaran dalam kehidupan sehari-hari pada pembelajaran daring juga dapat meningkatkan keterampilan proses sains. Hal ini berhubungan dengan tersedianya lembar kerja yang menggiring siswa untuk melakukan eksperimen. Penerapan lembar kerja eksperimen merupakan salah satu upaya untuk meningkatkan keterampilan proses sains siswa (Hikmawati et al. 2019). Untuk meningkatkan keterampilan tersebut, diperlukan pembinaan yang mampu mengarahkan siswa pada kegiatan yang berhubungan dengan keterampilan proses sains (Mayanty et al, 2018). Hal ini dapat dilakukan dengan pembelajaran dengan modul elektronik, karena modul elektronik sebagai bahan pembelajaran mandiri dapat disusun secara sistematis ke dalam unit-unit pembelajaran untuk mencapai tujuan pembelajaran tertentu, termasuk keterampilan proses sains.

Pembelajaran dengan modul elektronik untuk melatih keterampilan proses ilmiah juga dapat mengarahkan siswa menjadi lebih aktif, mengembangkan rasa tanggung jawab, serta meningkatkan metode penelitian dan pembelajaran (Gürses et al. 2015). Pembelajaran dengan modul elektronik untuk melatih keterampilan proses sains juga dapat mengarahkan siswa menjadi lebih aktif, mengembangkan rasa tanggung jawab, serta meningkatkan metode penelitian dan pembelajaran (Afifah et al, 2019). Keterampilan proses sains dapat melatih kemampuan atau kecakapan untuk melaksanakan suatu tindakan dalam belajar sains sehingga menghasilkan konsep, teori, prinsip, hukum maupun fakta atau bukti.

Dalam pelaksanaan penelitian ditemukan berbagai kendala yang menjadi keterbatasan dalam penelitian ini. Keterbatasan pertama yaitu aspek keterampilan proses sains yang diamati terbatas pada kemampuan observasi, perumusan hipotesis, interpretasi data, pengajuan pertanyaan, eksperimen, dan 
komunikasi. Hal ini karena keterbatasan waktu untuk mengukur seluruh indikator keterampilan proses sains dalam pembelajaran. Solusi untuk keterbatasan ini yaitu guru atau peneliti lanjutan diharapkan dapat menggunakan e-modul getaran dalam kehidupan sehari-hari pada pembelajaran daring dan mengukur berbagai indikator dari kemampuan proses sains.

Keterbatasan pertama adalah e-modul yang dikembangkan masih terbatas pada KD 3.11 dan 4.11 kelas $X$ semester 2 mengenai hubungan gaya dan geteran dalam kehidupan sehari-hari. Hal ini dikarenakan keterbatasan waktu peneliti dalam pembuatan e-modul satu semester. Solusi untuk keterbatasan ini adalah agar e-modul yang dikembangkan berdasarkan semua materi yang terdapat pada kelas $\mathrm{X}$ baik semester 1 maupun semester 2, sehingga mampu menghasilkan bahan ajar yang lebih lengkap.

\section{PENUTUP}

Berdasarkan hasil penelitian, dapat dinyatakan bahwa penggunaan e-modul getaran dalam kehidupan sehari-hari pada pembelajaran daring memiliki pengaruh yang signifikan terhadap peningkatan pengetahuan dan keterampilan proses sains siswa. Dengan demikian, dapat disimpulkan bahwa penggunaan e-modul getaran dalam kehidupan sehari-hari adalah efektif untuk meningkatkan pengetahuan dan keterampilan proses sains siswa.

\section{REFERENSI}

Afifah, R. N., Syaodih, E., Suhandi, A., Maftuh, B., Hermita, N., Handayani, H., Ningsih. A. R., Gumala, Y., \& Samsudin, A., "Develop children's science process skills through building activities in center of beam: optical geometry on focus," Journal of Physics: Conference Series, 1280(5), 1

\section{6/1280/5/052016. \\ doi:10.1088/1742-}

Ardiva, \& Andini. (2019). Pengembangan

E-Modul Fisika Berbasis Contextual

Teaching and Learning Untuk

Meningkatkan Keterampilan Proses sains Siswa SMA Kelas X Pada Materi

Usaha dan Energi, Impuls dan

Momentum. (Masters thesis).

Universitas Negeri Padang, Padang.

Asrizal., Hendri, A., Hidayati., Festiyed. (2018, 20 November). Penerapan Model Pembelajaran Penemuan Mengintegrasikan Laboratorium Virtual dan Hots untuk Meningkatkan Hasil Pembelajaran Siswa SMA Kelas XI. Edisi Publikasi Prociding Seminar PDS UNP 2018. Universitas Negeri Padang, Padang, Indonesia.

Asrizal., Sumarmin, R., Iswendi., \& Gustiya, T. (2014). Hasil Validasi Bahan Ajar Ict Sains Terpadu Model Terhubung Mengintegrasikan Nilai Karakter Untuk Pembelajaran Siswa SMP Kelas VIII. Prosiding Semirata 2014. Bogor, Indonesia.

Bilfaqih, Y., \& Qomarudin, N. (2015). Esensi Pengembangan Pembelajaran Daring. Sleman : Deepublish.

Darmaji., Astalini., Kurniawan, D., Parasdila, H., Irdianti., Subiyanto., Kuswanto., \& Ikhlas, M. (2019). EModule Based Problem Solving in Basic Physics Practicum for Science Process Skills. International Journal of Online and biomedical Engineering. 15(15), 4-17. https://doi.org/10.3991/ijoe.v15i15.10 $\underline{942}$

Desy, H.P., Risdianto,E., \& Sutarno. (2017). Identifikasi Keterlaksanaan

Praktikum Fisika SMA dan Pembekalan Keterampilan Abad 21. Semarang: Universitas PGRI Semarang.

Enrica, S.Y., \& Hardeli. (2019). Validitas Dan Praktikalitas E-Modul Sistem Koloid Berbasis Pendekatan Saintifik. Ranah Research: Journal of 
Multidicsiplinary Research and Development. 1(4). 812-820.

Febrilia., Ratnawulan., \& Usmeldi. (2019) Validity of integrated natural science teacher's book with immersed type that contain character on subject of bioelectrical energy by using science process skills approach. Journal of Physics Conference Series. 1185(1). 1-4. DOI:10.1088/17426596/1185/1/ 012076.

Gürses, A., Çetinkaya, S., Doğar, C., Şahin, E. (2015). Determination of levels of use of basic process skills of high school students. Procedia - Social and Behavioral Sciences, 191, 644-650. https://doi.org/10.1016/J.

SBSPRO.2015.04.243

Hikmawati., Kusmiyati., \& Sutrio. (2019). Penerapan Lembar Kerja Eksperimen Untuk Melatih Keterampilan Proses Sains Siswa Sma. Jurnal Pendidikan Fisika Dan Teknologi. 5(1), 167-172. Doi:Http://Dx.Doi.Org/10.29303/Jpft. V5i1.1062

Kuntarto, E. (2017). Keefektifan Model Pembelajaran Daring Dalam Perkuliahan Bahasa Indonesia Di Perguruan Tinggi. Journal Indonesian Language Education and Literature 3(1).99-110. DOI:http://dx.doi.org/ $\underline{10.24235 / \text { ileal.v3i1.1820 }}$

Muthmainnah., Rokhmat, J., \& 'Ardhuha, J., (2017). Pengaruh Penerapan Metode Pembelajaran Fisika Berbasis Eksperimen Virtual Terhadap Motivasi Dan Hasil Belajar Fisika Siswa Kelas X MAN 2 Mataram Tahun Ajaran 2014/2015. Jurnal Pendidikan Fisika Dan Teknologi. 3(1), 40-47.

Mayanty. S., Astra. I. M., \& Rustana, C. E. (2018). Pengembangan E-modul Fisika Berbasis Problem Based Learning (PBL) Untuk Meningkatkan Keterampilan Proses Sains Siswa SMA. Prosiding Seminar Nasional Quantum \#25 (2018). Universitas Negeri Jakarta, Indonesia.
Pohan, A.E. (2020). Konsep Pembelajaran Daring Berbasis Konsep Ilmiah. Purwodadi. CV. Sarnu Untung.

Prastowo, A (2011). Panduan Kreatif Membuat Bahan Ajar Inovatif: Menciptakan Metode Pembelajaran yang Menarik dan Menyenangkan. Yogyakarta: DIVA Press.

Serevina, V., Sunaryo. Raihanati. Astra, Sari, I.M., Juwita, I. (2018). Development of E-Module Based on Problem Based Learning (PBL) on Heat and Temperature to Improve Student's Science Process Skill. The Turkish Online Journal of Educational Technology - July 2018, 17(3). 26-36

Sugianto, D., Abdullah, A. G., Elvyanti, S., \& Muladi, Y. (2013). Modul Virtual: Multimedia Flipbook Dasar Teknik Digital. Innovation of Vocational Technology Education (2017). 9(2). 101-116. DOI: 10.17509/invotec. v9i2.4860

Tawil, M., \& Liliasari. (2014). Keterampilan-Keterampilan Sains dan Implementasinya dalam Pembelajaran IPA. Makassar: UNM.

Tazkiyah, A., Sulur., \& Fawaiz, S., (2020). Pengembangan Modul Elektronik Dengan Feedback Berbasis Android Materi Suhu Dan Kalor Untuk Siswa SMA/MA. Jurnal Pendidikan Fisika dan Teknologi (JPFT. 6(1), 31-38. DOI:http://dx.doi.org/10.29303/jpft.v $6 \mathrm{i} 1.1731$

Turiman, P., Omar, J., Daud, A. M., \& Osman. (2011). Fostering the 21st century skills through scientific literacy and science process skills, Procedia - Social and Behavioral Sciences 59 (2012). Universiti Kebangsaan Malaysia, Malaysia.

Wijaya, E.Y., Sudjimat, D.A., Nyoto, A. (2016). Transformasi Pendidikan Abad 21 Sebagai Tuntutan Pengembangan Sumber Daya Manusia Di Era Global. Prosiding Seminar Nasional Pendidikan Matematika 2016. Universitas Kanjuruhan Malang. Indonesia 